\title{
Do Patients Want Help Addressing Social Risks?
}

\author{
Emilia H. De Marchis, MD, MAS, Hugh Alderwick, BA, and \\ Laura M. Gottlieb, MD, MPH
}

Evaluations of health care-based screening programs for social risks often report that a relatively small proportion of patients screening positive for social risk factors are interested in receiving assistance from their health care teams to address them. The relatively low number of patients who desire assistance is relevant to the growing number of initiatives in US health care settings designed to collect data on and address patients' social risks. We highlight multiple studies that have found differences between positive risks screens and desire for assistance. We explore possible explanations for those differences-focusing on the fallibility of screening tools as well as patient preferences, priorities, and lived experiences-and the potential implications for health equity. (J Am Board Fam Med 2020;33:170-175.)

Keywords: Delivery of Health Care, Health Equity, Patient Care Team, Patient Preference, Population Health, Risk Factors, Social Determinants of Health, Social Work

There is growing recognition that patients' social contexts influence health outcomes more than medical care access or quality. ${ }^{1-3}$ As a result, some US health care systems are increasingly adopting initiatives to identify social risk and to help reduce the burden of social risks faced by their patients-for example, by helping those who are hungry access food. ${ }^{3-7}$ These kinds of screening and intervention programs have been endorsed by multiple medical professional organizations and are the topic of a recent National Academy of Sciences, Engineering, and Medicine consensus committee. ${ }^{8-13}$

Since many of these programs are based in settings serving underserved, low-income populations, it is not surprising that studies of these programs

From the Department of Family \& Community Medicine, University of California-San Francisco, San Francisco, CA (EHD, LMG); Health Foundation, London, UK (HA).

Funding: This publication was supported by a fellowship training grant by the National Research Service Award (NRSA) T32HP19025. Its contents are solely the responsibility of the authors and do not represent the official views of NRSA.

Conflicts of interests: None.

Corresponding author: Emilia H. De Marchis, MD, MAS, University of California-San Francisco, 3333 California Street, Suite 465, San Francisco, CA 94118 (E-mail: emilia. demarchis@ucsf.edu).

See Related Articles on Pages 176 and 179. generally report that participants have high rates of social risks, such as food insecurity or housing instability. $^{7,14}$ Multiple studies also have shown that patients report feeling comfortable completing social risk assessments (typically written questionnaires) on these topics. ${ }^{15-18} \mathrm{~A}$ more complex finding from these programs, however, is that many patients who screen positive for social risks subsequently decline assistance to address those risks from health care team members..$^{5-7,14,19-26}$ In a recent community health center study, for instance, over $90 \%$ of patients screened positive for at least one social risk factor, but only about $20 \%$ wanted assistance from health center staff. ${ }^{7}$ In other studies, differences are less dramatic, but the theme has surfaced across multiple settings. ${ }^{5,6,14,19-26}$ (Table 1).

Why do patients who screen positive for social risks decline assistance? And what does this mean for health systems planning to implement social risk screening and related social care interventions? The difference between screening positive and interest in help is intriguing for its dual implications. On the one hand, it may increase social risk program availability and improve health equity by lowering the feasibility barriers of introducing social risk assessments in clinical settings (assuming that it is less costly to provide services in response to social risks if fewer people want them). On the other, it may widen health inequities if those who accept assistance are systematically different from those who 
Table 1. Discrepancy Between Positive Social Risk and Interest in Assistance: Examples from US Health Services Published Research*

\begin{tabular}{|c|c|c|c|}
\hline Authors (Publication Years) & Social Risk Domain & Positive Screen, \% & Positive Screen Interested in Assistance, $\%^{\dagger}$ \\
\hline Bottino et al. $(2017)^{19}$ & Food insecurity & 32 & 54 \\
\hline \multirow[t]{6}{*}{ Eismann et al. $(2018)^{26}$} & Food insecurity & 11 & 90 \\
\hline & Harsh punishment & 1 & 70 \\
\hline & Parental stress & 14 & 79 \\
\hline & Parental depression & 9 & 74 \\
\hline & Parental substance use & $<1$ & 50 \\
\hline & Safety concern & 6 & 71 \\
\hline Fox et al. $(2016)^{20}$ & Food insecurity & $34^{\ddagger}$ & $75^{\S}$ \\
\hline \multirow[t]{7}{*}{ Garg et al. $(2010)^{25}$} & Childcare & 29 & $64^{\|}$ \\
\hline & Education & 9 & \\
\hline & Food insecurity & 11 & \\
\hline & Housing instability & 12 & \\
\hline & Insurance & 6 & \\
\hline & Public benefits & 5 & \\
\hline & Utilities & 7 & \\
\hline Gold et al. $(2018)^{7}$ & Multiple social risk factors & $91 ; 98^{\|, \pi}$ & $15 ; 21$ \\
\hline \multirow[t]{6}{*}{ Hassan et al. $(2015)^{14}$} & Education & $14^{\#}$ & 56 \\
\hline & Financial strain & 10 & 83 \\
\hline & Food insecurity & 29 & 38 \\
\hline & Housing instability & 34 & 37 \\
\hline & Safety concern & 16 & 16 \\
\hline & Substance use & 20 & 6 \\
\hline Knowles et al. $(2018)^{21}$ & Food insecurity & 16 & 56 \\
\hline Martel et al. $(2018)^{22}$ & Food insecurity & $-{ }^{\dagger \dagger}$ & 63 \\
\hline Schickedanz et al. $(2019)^{23}$ & Multiple social risk factors & $53^{\|}$ & $48^{\|}$ \\
\hline Swavely et al. $(2018)^{5}$ & Food insecurity & 27 & 48 \\
\hline \multirow[t]{6}{*}{ Tong et al. $(2018)^{6}$} & Education & 2 & 67 \\
\hline & Financial strain & 11 & 0 \\
\hline & Food insecurity & 7 & 22 \\
\hline & Housing instability & 4 & 20 \\
\hline & Safety concern & 2 & 100 \\
\hline & Social isolation & 2 & 50 \\
\hline Uwemedimo and May $(2018)^{24}$ & Multiple social risk factors & $43^{\|}$ & 49 \\
\hline
\end{tabular}

*These are examples from previously published literature but do not reflect findings from a systematic literature review.

${ }^{\dagger}$ Depending on study outcome, interest signifies acceptance of referral, intervention enrollment, or similar metric. Type of assistance offered differed by study and may account for some of the noted fluctuations in interest in assistance between studies.

${ }^{\ddagger}$ Thirty-four percent were eligible for/offered a referral to food bank based on being food insecure or having public insurance, and not already enrolled in Supplemental Nutrition Assistance Program (SNAP). Only 24\% screened positive for food insecurity.

$\$ 75 \%$ of those eligible for referral, agreed to be referred, but only $8 \%$ were confirmed to have enrolled in the food bank.

"Authors did not provide information to separate by domain.

${ }^{\top}$ Results reported are for overall percentage of participants with $\geq 1$ endorsed social risk and percentage of those who were interested in assistance, from two different community health centers.

\#Showing the percentage of participants who screened positive for a "major problem" in each domain.

** Included nutrition/bodyweight.

${ }^{\dagger \dagger}$ Authors only reported the total number of patients with food insecurity who accepted a referral.

do not. ${ }^{27}$ In this commentary, we surface possible explanations for why patients decline social care assistance and the potential equity implications of alternative explanations (Table 2).
Discrepancies between positive social risk screening and desire for help could simply indicate that screening is fallible. There are surprising and important gaps in the psychometric data on existing 
Table 2. Potential Sources of Discrepancy Between Patients' Social Risk Screening Results and Interest in Assistance

\begin{tabular}{|c|c|c|}
\hline Source & Significance & Implications for Equity \\
\hline \multicolumn{3}{|l|}{ Validity of Social Risk Screening } \\
\hline $\begin{array}{l}\text { Lack of psychometric testing of } \\
\text { social risk screening tools }\end{array}$ & $\begin{array}{l}\text { Low specificity may exaggerate social } \\
\text { risks in some populations (high false } \\
\text { positive rate), while underestimating } \\
\text { them in others (low sensitivity; high } \\
\text { false-negative rate). }\end{array}$ & $\begin{array}{l}\text { Social risk screening tools may be less valid/ } \\
\text { reliable in different patient populations. If } \\
\text { resources are distributed based on } \\
\text { screening results, there may be a } \\
\text { disparate distribution of resources. }\end{array}$ \\
\hline $\begin{array}{l}\text { Use of social risk screening tool as a } \\
\text { diagnostic tool }\end{array}$ & $\begin{array}{l}\text { If health care teams rely on a screening } \\
\text { tool to diagnose social risks, they may } \\
\text { offer resources to patients without } \\
\text { clarifying patients' perceived needs } \\
\text { and priorities (relates to psychometric } \\
\text { properties of tools, but also patient } \\
\text { preferences and priorities). }\end{array}$ & $\begin{array}{l}\text { Health care teams may draw incorrect } \\
\text { conclusions about the needs of their } \\
\text { patients based on improper use of } \\
\text { screening tools, along with a lack of } \\
\text { patient-centered implementation. If } \\
\text { vulnerable patient groups have a limited } \\
\text { understanding of what is being offered, or } \\
\text { feel less empowered to accept resources, } \\
\text { they may disproportionately decline } \\
\text { assistance. }\end{array}$ \\
\hline \multicolumn{3}{|l|}{ Lack of Patient Interest in Assistance } \\
\hline $\begin{array}{l}\text { Patient does not think health care is } \\
\text { an appropriate setting for social } \\
\text { care interventions }\end{array}$ & $\begin{array}{l}\text { Patient experiences within health care } \\
\text { and with social care in general may } \\
\text { influence their view on the } \\
\text { appropriateness of social care } \\
\text { interventions in health care (e.g. prior } \\
\text { discrimination). }\end{array}$ & $\begin{array}{l}\text { Marginalized patients may be more wary of } \\
\text { the health care system's involvement in } \\
\text { their social sphere, leading them to } \\
\text { decline assistance. }\end{array}$ \\
\hline $\begin{array}{l}\text { Patient already getting assistance } \\
\text { elsewhere }\end{array}$ & $\begin{array}{l}\text { If a patient's needs are already being at } \\
\text { least partially addressed elsewhere, } \\
\text { additional resources from the health } \\
\text { care system may not be needed. } \\
\text { Patients may, however, be unaware of } \\
\text { additional supports they are eligible } \\
\text { for that could provide further benefit. }\end{array}$ & $\begin{array}{l}\text { Without clarifying where patients are } \\
\text { getting support to identify potential gaps } \\
\text { or vulnerabilities, less empowered } \\
\text { patients may be less able to seek or ask } \\
\text { about additional support. }\end{array}$ \\
\hline $\begin{array}{l}\text { Patient does not prioritize social } \\
\text { care during clinical encounters }\end{array}$ & $\begin{array}{l}\text { Patients may have competing interests } \\
\text { for visits. }\end{array}$ & $\begin{array}{l}\text { Patients with more complex medical needs } \\
\text { and/or poor health literacy may be less } \\
\text { interested in discussing social risks, } \\
\text { though risks may have profound } \\
\text { implications for their medical care and } \\
\text { health outcomes. }\end{array}$ \\
\hline
\end{tabular}

social risk screening tools. ${ }^{28}$ It is possible that the social risks captured by current screening tools do not meet a threshold that respondents believe warrants intervention, or-given that some screening questions ask about experiencing social risks in the past 12 months ${ }^{29-31}$ - tools could be picking up risks no longer of active concern. Most comprehensive social risk screening tools being used in clinical settings have not undergone reliability and validity testing comparable to other clinical screening tools. ${ }^{28}$ In other cases, single domain measures like the Hunger Vital Sign ${ }^{\text {TM }}$ have been validated in specific clinical populations but not across populations or in the context of a more comprehensive assessment. ${ }^{32}$ Even when they have been studied, comprehensive social risk screening tools are commonly adapted, used in different populations, or combined with other measures without further validity testing. ${ }^{33}$ Lower rates of interest in assistance may thus be a result of low specificity of current measurements; in other words, screening tools might be capturing false positives. There is no consensus about the "right" specificity and sensitivity for social risk screening tools-likely because those numbers will differ based on the prevalence of social risk factors in a given patient population, ${ }^{34}$ the intended goals of screening, and the availability of related health care and community resources.

The gaps in evidence on psychometric validity are exacerbated by the interpretation of screening results. By design, a screening tool should prompt further assessments to "diagnose" a medical condition. $^{35}$ For instance, in depression screening, answering affirmatively to either question in the 2item Patient Health Questionnaire (PHQ) signals that a patient is at risk for depression; it is not used to diagnose depression. ${ }^{36,37}$ In social risk screening, positive results are often conflated with diagnosis of 
a social need-two related but distinct concepts. ${ }^{38}$ In part, this conflation is due to the rapid expansion of work around health care-based social risk activities without grounding these innovative screening practices with substantial evidence around diagnostic criteria and interventions. ${ }^{35}$

The gap between social risk screening results and desire for assistance might not solely be the result of low screening validity. It may instead be that patients do not want or expect help from health care teams around social risk factors. In fact, we know relatively little about how patients prioritize social needs relative to medical concerns; whether patients perceive health care as an appropriate forum for social care interventions; and where patients currently obtain social services and their experiences with those social services agencies.

Patients' interest in assistance is likely shaped by prior experiences with health care and social service sectors, including their experiences with/trust in providers, ${ }^{21}$ experiences of discrimination, and experiences obtaining resources in the past. $4,5,24,26,39$ These together can affect hope and hopelessness. Interventions that can increase the likelihood of obtaining resources have been the focus of previous publications, though few have examined the impacts on specific subpopulations. ${ }^{5,7,14,19-21,23-26,39-43}$ Positive prior experiences do influence patient perspectives of health care-based social care activities. ${ }^{17,18}$ But interest in assistance- and the impact of related interventions-also may be influenced by cultural and demographic characteristics (eg, perceived stigma associated with receipt of benefits, documentation status, or preferred language). Some of these factors also may be amenable to health care interventions. As one example, the Oregon Primary Care Association has suggested strategies to strengthen patient-centered implementation of social risk screening and interventions in ways that are likely to increase patient acceptability. ${ }^{44}$

Other factors that can influence patients' interest in assistance depend more on forces outside the health care sector. For example, participants in multiple studies report eligibility for government resources as a barrier to accessing assistance. ${ }^{5,20-22}$ Patients who know they are ineligible for-or are otherwise wary of ${ }^{45}$ - the benefits of government program enrollment may therefore be less likely to express interest in assistance. Patients may also be less likely to express interest in assistance if they perceive social services in the community to be insufficient or unavailable. To overcome these external barriers will require local, state, and federal policy changes. A recent National Academies of Medicine report on Integrating Social Care into the Delivery of Health Care incorporates strategies for health care sector engagement in policy and community-level interventions that could in turn affect patients' interest in assistance. ${ }^{13}$

A foundational premise underlying social interventions in health care settings is that addressing patients' social risks should improve health equity. ${ }^{46-49}$ But if interest in assistance-or lack of interest in assistance-is driven by systemic differences between patients and/or contexts, these programs might unintentionally exacerbate inequities, especially if those most likely to benefit from services are least likely to access them. Currently we know relatively little about the differences in interest in social care interventions by patient race, ethnicity, age, gender, sexual orientation, language, and immigration status. ${ }^{24}$ Nor do we understand how the health care context, including the staff's cultural and linguistic competency, contributes to patients' interest in assistance. Future research should examine the impacts and comparative impacts of health carebased initiatives to identify and address social conditions on health and health inequities, ${ }^{50}$ including by examining whether uptake of services is primarily a measurement problem or more fundamentally related to the accessibility, content, or quality of related interventions. ${ }^{51}$

To see this article online, please go to: http://jabfm.org/content/ 33/2/170.full.

\section{References}

1. Adler NE, Stewart J. Health disparities across the lifespan: meaning, methods, and mechanisms. Ann N Y Acad Sci 2010;1186:5-23.

2. Stringhini S, Sabia S, Shipley M, et al. Association of socioeconomic position with health behaviors and mortality. JAMA 2010;303:1159-66.

3. McGinnis JM, Williams-Russo P, Knickman JR. The case for more active policy attention to health promotion. Health Aff (Millwood) 2002; 21:78-93.

4. Stenmark SH, Steiner JF, Marpadga S, DeBor M, Underhill K, Seligman H. Lessons learned from implementation of the food insecurity screening and referral program at Kaiser Permanente Colorado. Perm J 2018;22:18-093. 
5. Swavely D, Whyte V, Steiner JF, Freeman SL. Complexities of addressing food insecurity in an urban population. Popul Health Manag 2019;22: 300-7.

6. Tong ST, Liaw WR, Kashiri PL, et al. Clinician experiences with screening for social needs in primary care. J Am Board Fam Med 2018;31:351-63.

7. Gold R, Bunce A, Cowburn S, et al. Adoption of social determinants of health EHR tools by community health centers. Ann Fam Med 2018;16:399-407.

8. American Academy of Family Physicians. The EveryONE Project: Screening Tools and Resources to Advance Health Equity. 2018. Available from: https://www.aafp.org/patient-care/social-determinantsof-health/everyone-project/tools.html\#patients. Accessed August 6, 2018.

9. American Academy of Family Physicians. Neighborhood Navigator. 2018. Available from: https://www. aafp.org/patient-care/social-determinants-of-health/ everyone-project/neighborhood-navigator.html. Accessed August 6, 2018.

10. Council on Community Pediatrics. Poverty and child health in the United States. Pediatrics 2016;137:

11. Daniel H, Bornstein SS, Kane GC, Physicians H. Addressing social determinants to improve patient care and promote health equity: An American College of Physicians position paper. Ann Intern Med 2018;168:577-8.

12. Arnett DK, Blumenthal RS, Albert MA, et al. ACC/AHA Guideline on the primary prevention of cardiovascular disease. J Am Coll Cardiol 2019;74:e177-e232.

13. National Academies of Sciences, Engineering, and Medicine. Integrating social care into the delivery of health care: moving upstream to improve the nation's health. Washington, DC: National Academies Press (US); 2019.

14. Hassan A, Scherer EA, Pikcilingis A, et al. Improving social determinants of health: effectiveness of a Web-based intervention. Am J Prev Med 2015;49:822-31.

15. Hassan A, Blood EA, Pikcilingis A, et al. Youths' health-related social problems: concerns often overlooked during the medical visit. J Adolesc Health 2013;53:265-71.

16. Wylie SA, Hassan A, Krull EG, et al. Assessing and referring adolescents' health-related social problems: qualitative evaluation of a novel web-based approach. J Telemed Telecare 2012;18:392-8.

17. De Marchis EH, Hessler D, Fichtenberg C, et al. Part I: A quantitative study of social risk screening acceptability in patients and caregivers. Am J Prev Med 2019;57:S25-S37.

18. Byhoff E, De Marchis EH, Hessler D, et al. Part II: A qualitative study of social risk screening acceptability in patients and caregivers. Am J Prev Med 2019;57:S38-46.
19. Bottino CJ, Rhodes ET, Kreatsoulas C, Cox JE, Fleegler EW. Food insecurity screening in pediatric primary care: can offering referrals help identify families in need? Acad Pediatr 2017;17:497-503.

20. Fox CK, Cairns N, Sunni M, Turnberg GL, Gross AC. Addressing Food insecurity in a pediatric weight management clinic: a pilot intervention. J Pediatr Health Care 2016;30:e11-e15.

21. Knowles M, Khan S, Palakshappa D, et al. Successes, challenges, and considerations for integrating referral into food insecurity screening in pediatric settings. J Health Care Poor Underserved 2018;29:181-91.

22. Martel ML, Klein LR, Hager KA, Cutts DB. Emergency department experience with novel electronic medical record order for referral for food resources. West J Emerg Med 2018;19:232-7.

23. Schickedanz A, Sharp A, Hu YR, et al. Impact of social needs navigation on utilization among high utilizers in a large integrated health system: a quasi-experimental study. J Gen Intern Med 2019;34:2382-9.

24. Uwemedimo OT, May H. Disparities in utilization of social determinants of health referrals among children in immigrant families. Front Pediatr 2018;6:207.

25. Garg A, Sarkar S, Marino M, Onie R, Solomon BS. Linking urban families to community resources in the context of pediatric primary care. Patient Educ Couns 2010;79:251-4.

26. Eismann EA, Theuerling J, Maguire S, Hente EA, Shapiro RA. Integration of the Safe Environment for Every Kid (SEEK) model across primary care settings. Clin Pediatr (Phila) 2019;58:166-76.

27. Veinot TC, Mitchell H, Ancker JS. Good intentions are not enough: how informatics interventions can worsen inequality. J Am Med Informat Assoc 2018;25:1080-8.

28. Henrikson NB, Blasi PR, Dorsey CN, et al. Psychometric and pragmatic properties of social risk screening tools: a systematic review. Am J Prev Med 2019;57:S13-S24.

29. The Accountable Health Communities HealthRelated Social Needs Screening Tool. 2018. Available from: https://innovation.cms.gov/files/ worksheets/ahcm-screeningtool.pdf. Accessed March $18,2019$.

30. PRAPARE. 2016. Available from: http://www.nachc. org/research-and-data/prapare/. Accessed November 20, 2019.

31. Cartier Y, Fichtenberg CM, Gottlieb LM. Screening tools comparison. In: SIREN, ed. sirenetwork.ucsf.edu: San Francisco, CA: University of California; 2018.

32. Hager ER, Quigg AM, Black MM, et al. Development and validity of a 2 -item screen to identify families at risk for food insecurity. Pediatrics 2010;126:e26-e32.

33. Rabin BA, Lewis CC, Norton WE, et al. Measurement resources for dissemination and 
implementation research in health. Implementation Sci 2016;11:9.

34. Garg A, Sheldrick C, Dworkin PH. The inherent fallibility of validated screening tools for social determinants of health. Academic pediatrics 2018;18: 123-4.

35. Wilson JMG, Jungner G. Principles and practice of screening for disease France. London, UK: World Health Organization; 1968.

36. Arroll B, Goodyear-Smith F, Crengle S, et al. Validation of PHQ-2 and PHQ-9 to screen for major depression in the primary care population. Ann Fam Med 2010;8:348-53.

37. Institute of Medicine. Capturing social and behavioral domains and measures in electronic health records: phase 2. Atlanta, GA: The National Academies Press; 2014.

38. Alderwick H, Gottlieb LM. Meanings and misunderstandings: A social determinants of health lexicon for health care systems. Milbank Q 2019; 97:407-419.

39. Marpadga S, Fernandez A, Leung J, Tang A, Seligman H, Murphy EJ. Challenges and successes with food resource referrals for food-insecure patients with diabetes. Perm J 2019;23.

40. Sharma AE, Knox M, Mleczko VL, Olayiwola JN. The impact of patient advisors on healthcare outcomes: a systematic review. BMC Health Serv Res 2017;17:693.

41. Gottlieb L, Fichtenberg C, Alderwick H, Adler N. Social determinants of health: What's a health care system to do? J Healthcare Manage/Am Coll Healthcare Exec 2019;64:243-57.

42. De Marchis EH, Torres JM, Benesch T, et al. Interventions addressing food insecurity in health care settings: a systematic review. Ann Fam Med 2019;17:436-47.
43. Tung EL, Abramsohn EM, Boyd K, et al. Impact of a low-intensity resource referral intervention on patients' knowledge, beliefs, and use of community resources: results from the CommunityRx trial. J Gen Intern Med 2019 [Epub ahead of print].

44. Oregon Primary Care Association. Empathic Inquiry. 2019. Available from: https://www.orpca. org/initiatives/empathic-inquiry. Accessed March 31, 2019.

45. Kaiser Family Foundation. Changes to "public charge" inadmissibility rule: implications for health and health coverage. In: Kaiser Family Foundation, ed. Available from: https://www.kff.org/disparitiespolicy/fact-sheet/public-charge-policies-forimmigrants-implications-for-health-coverage/2019.

46. Adler NE, Glymour MM, Fielding J. Addressing social determinants of health and health inequalities. JAMA 2016;316:1641-2.

47. Marmot M, Allen JJ. Social determinants of health equity. Am J Public Health 2014;104:S517-S519.

48. Penman-Aguilar A, Talih M, Huang D, Moonesinghe R, Bouye K, Beckles G. Measurement of health disparities, health inequities, and social determinants of health to support the advancement of health equity. J Public Health Manag Pract 2016; 22:S33-S42.

49. Moscrop A, Ziebland S, Roberts N, Papanikitas A. A systematic review of reasons for and against asking patients about their socioeconomic contexts. Int J Equity Health 2019;18:

50. Thomas SB, Quinn SC, Butler J, Fryer CS, Garza MA. Toward a fourth generation of disparities research to achieve health equity. Annu Rev Public Health 2011;32:399-416.

51. Gottlieb LM, Alderwick H. Integrating social and medical care: could it worsen health and increase inequity? Ann Fam Med 2019;17:77-81. 